\title{
Policy-Making Considerations for Ethical and Sustainable Economic Development
}

\author{
Tipakorn Senathip ${ }^{1} \Varangle$ \\ Bahaudin G. Mujtaba ${ }^{2}$ (D) \\ Frank J. Cavicos \\ 'Ramkhamhaeng University, Thailand \\ ${ }^{2,3}$ Nova Southeastern University, USA
}

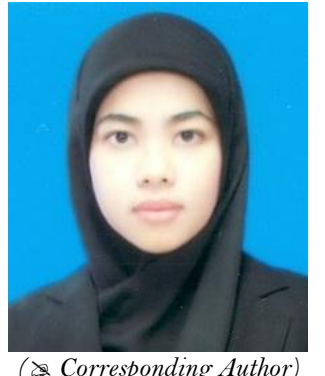

\begin{abstract}
Leaders of both private and public sector organizations play an important role in bringing about positive and necessary developments in society. This leadership is especially an important consideration for public sector policy-makers to look at the long-term with regards to their policy-making in economic development. Citizens of any society, but particularly an agrarian one, tend to depend on the availability of natural and local resources for their survival and independence. Furthermore, economic development is important for communities and societies to live in a sustainable manner using local resources in a prudent yet efficacious manner. This study looks at the importance of policy-making for economic progress; the study examines the influences on policy-making; and seeks to ascertain how local leaders can take a developmental role in creating and promoting sustainability approaches for citizens, particularly local farmers and consumers. The study, moreover, examines the role of ethics as a branch of philosophy on leadership and the policy-making decision process. The study treats both government and private sector business leaders. Suggestions and recommendations are provided to both types of leaders to help them make effective, moral, and sustainable policy decisions.
\end{abstract}

Keywords: Policy, Policy-making, Sustainability, Social responsibility, Stakeholders, Ethics, Morality, Leadership.

Citation | Tipakorn Senathip; Bahaudin G. Mujtaba; Frank J. Cavico (2017). Policy-Making Considerations for Ethical and Sustainable Economic Development. Economy, 4(1): 7-14.

History:

Received: 24 November 2016

Revised: 26 December 2016

Accepted. 18 April 2017

Published: 21 August 2017

Licensed: This work is licensed under a Creative Commons Attribution 3.0 License (cc)

Publisher:Asian Online Journal Publishing Group
Contribution/Acknowledgement: All authors contributed to the conception and design of the study.

Funding: This study received no specific financial support

Competing Interests: The authors declare that they have no conflict of interests.

Transparency: The authors confirm that the manuscript is an honest, Transparency: The authors confirm that the manuscript is an honest, features of the study have been omitted; and that any discrepancies from the features of the study have been omit
study as planned have been explained.

study as planned have been explained.
Ethical: This study follows all ethical practices during writing.

\section{Contents}

1. Introduction

2. Policy-Making and Development ...8

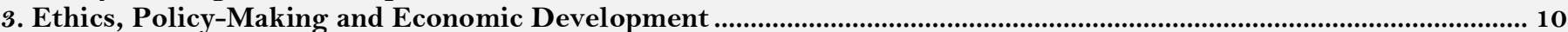

4. Social Responsibility, Sustainability, and Economic Development ….......................................................................... 1 1

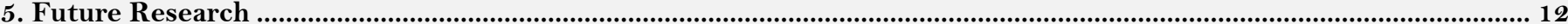

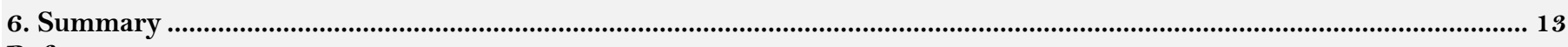

References...

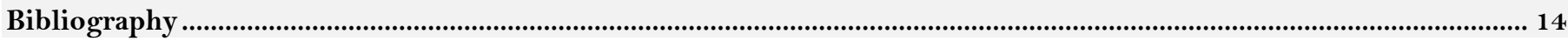




\section{Introduction}

Over the past decade, we see many modern researchers focusing on the responsibility of taking care of local communities, societies, and the planet by being "sustainable" in everything we do (Mujtaba, 2014). In some cases, we have seen friendly support, yet at times angry protests, when people are not happy with their current living situation; and consequently want positive changes in their lives, work environment, or the physical environment itself (Senathip, 2015). Fortunately, many people today are now being very socially responsible by voluntarily trying to reduce waste, reuse what they can, recycle as much as possible, renew by planting seeds or trees to replenish natural resources, and by respecting the environment, and thereby striving to keep it "clean and green" (Cavico and Mujtaba, 2016).

The critical question herein is to attempt to determine what role do public and private policies play in making local leaders and citizens aspire to a higher level of sustainability consciousness in order to produce effective economic development in society in a sustainable manner. It makes one wonder if morality, ethics and sustainability are all linked together. In other words, it might be possible that people with higher levels of sustainability consciousness might also have higher level of moral maturity. Furthermore, such individuals might be more likely to work in the public sector organizations for the intrinsic reasons (perhaps both "selfish" as well as altruistic) to help people, their communities, and society as whole to develop economically and to prosper. Accordingly, focusing on better understanding sustainability is a productive area of research for leadership, policymaking, ethics, as well as operational efficiency and effectiveness, and especially so in a sufficiency economy (UTantada et al., 2016). The "good news" is that many policy-makers in government as well as decision-makers in the private sector are now considering not "merely" whether their sound decisions are legal but also whether they are socially responsibility, sustainable, and moral. All the preceding values emerge as critical considerations as for leaders and policy-makers as they establish rules and precepts to govern the behavior of individuals and organizations in promoting sustainable economic development.

Mujtaba (2015) defines sustainability as "the ability of an organization and its employees to effectively and efficiently manage their core economic responsibilities in maximizing long-term value, while proactively respecting the environment and being accountable to all stakeholders in a transparent and timely manner" (Mujtaba et al., 2016). Mujtaba's long-term view of sustainability will be used in this study since highly ethical people are likely to be driven by decisions that respect the environment while enhancing the quality of life for everyone.

\section{Policy-Making and Development}

According to Rissmiller (2000) many writers and researchers have analyzed the concept of public policy; and as such they have reflected upon and asked how we can understand the "incredibly complex" process of policy change. Of course, there are many models and "answers" which have made important contributions to this understanding, but a good majority of them tend to rely on theory that is general in scope or, conversely, very narrow and specific to a particular agency's decision-making processes. As such, public policy theories are difficult to apply to all situations and cases. Some models are reliant on a single case which may have a limited scope of utility; yet other models are derived from multiple regression or even more sophisticated statistical analysis which disregards dynamic change and situational variables. Therefore, some scholars believe that the "scientific approaches to the study of policy-making processes are ill-designed to confront the apparently tremendous influence of personalities and chance events, the unique features of policies, and the unique and diverse range of environments in which policy is made" (Rissmiller, 2000). Rissmiller and other authors have recommended that the goal of policy theory should be to assist in understanding the role of causal elements in policy development regardless of whether they appear to be irregular and diverse or uniform and predictable. Thus, it is recommended that political scientists need to see "holistically" and as a result to utilize "systems-thinking" in their developmental policies. Unfortunately, "systems-thinking" and dynamics are not taught in most political science curriculums and programs. However, "systems-thinking" and dynamics have thrived in business applications as a result of the continuing work and commitment by people like Peter Senge and others at the Massachusetts Institute of Technology's (MIT) Sloan School of Management.

Theory-building and "systems analysis" have generated considerable interest in political sciences over the past century, notably in 1965, as stimulated by David Easton's writings on “A Systems Analysis of Political Life." Easton's work has been influential in that systems analysis has been identified as one of a handful of primary approaches to the study of political science and public policy (Susser, 1992; Anderson, 1997; Dye, 1998; Rissmiller, 2000).

According to researchers and writers (Jenkins, 1978) public policy is defined differently by different authors, including the following:

1. Public policy is whatever govrnments choose to do or not to do.

2. Public policy consists of political decisions for implementing pro-grams to achieve societal goals.

3. Public policy is a purposive course of action followed by government in dealing with some topic or mater of public concern.

4. Public policy is the authoritative allocation of values for the whole society.

In one article, public policy is defined "as a set of interrelated decisions taken by a political actor or group of actors concerning the selection of goals and the means of achieving them within a specified situation where those decisions should, in principle, be within the power of those actors to achieve" (Jenkins, 1978). Such a definition is not an all-encompassing as it does not build implementation into the policy. As such, one does not always consider how a policy might be implemented. This definition makes clear that a "policy is more than a single decision," as it can involve many actors, stakeholders, or constituent groups. Policy-making often involves a pattern of actions that extend over time and thus it might go through many decisions. Nonetheless, some critical points for consideration of such a definition and concomitant model can include the following elements:

- It integrates the possibility of inaction (the decision not to move).

- It separates policy from ambition.

- It links policy decisions to available resources. 
All policies tend to have multiple direct and indirect stakeholders. A stakeholder (actor or constituent group) can be any person, group or institution that has an interest in a development activity, project or program. The stakeholder definition includes intended beneficiaries and intermediaries, "winners" or "losers," and those involved or excluded from the decision-making or policy-making process. Stakeholders must have a high level of trust in policies in order to support it Ping et al. (2012). Therefore, public policy should be considered as much more than simply governmental outputs, because simply focusing on output alone may result in a partial and incomplete view of the dynamics and totality of public policy. Policy analysts should deal with the separation of the following: a) policy content - the substance of policy and b) policy process - the given set of methods, strategies, and techniques by which a policy is made (Jenkins, 1978).

The simplest and most frequently used model was first offered by Harold Laswell and eventually adopted and used by others is the schematic presentation of process perspective on policy. This simple model had linear steps or stages of initiation, information, consideration, decision, implementation, evaluation, and termination, with some "feedback" between the four initial stages (see Figure 1). Jenkins (1978) explained that this model operates based on the assumption that policy is created through logical and linear path from initiating the policy, implementing it and then eventually making a decision to proceed with the policy proposal or end it.

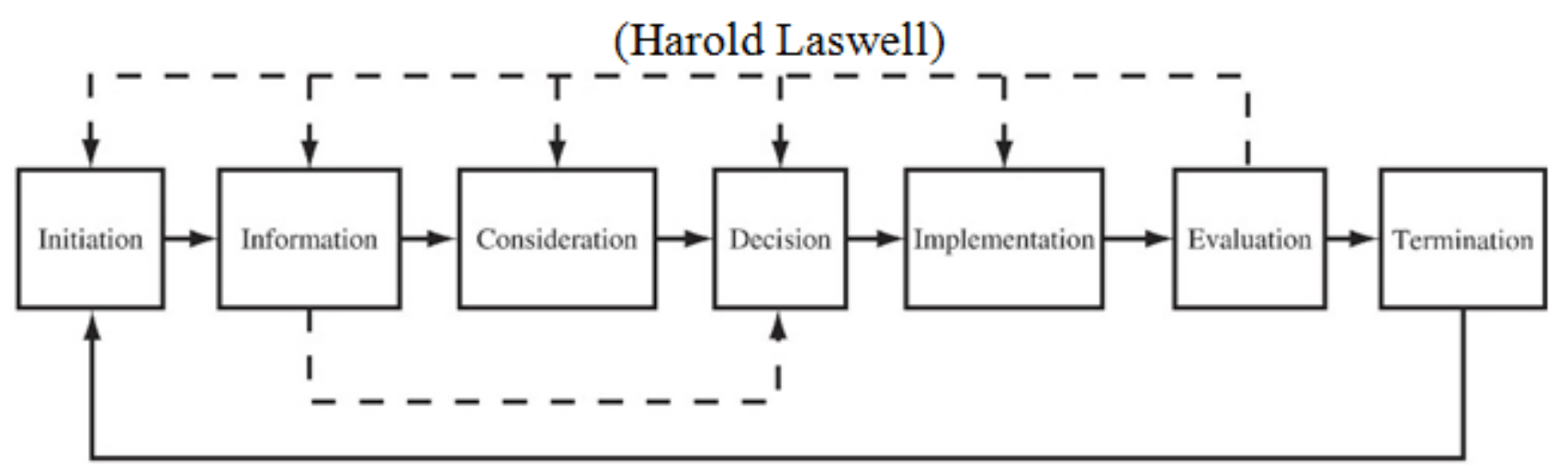

Source: Jenkins (1978)

Figure-1. Policy-Making

Some researchers, however, have argued that it might be better to consider the policy process in terms of input-output model of a political system. As such, another model was derived from the work of David Easton. The focus of this approach was directed at the dynamics and processes of a political system operating with diverse and changing environments. Moreover, according to Jenkins (1978) the political system operating in its environment has several major dimensions, including:

a) Policy demands: demands for action that arise from inside as well as outside the political systems.

b) Policy decisions: Authoritative rather routine decisions made by the political authorities.

c) Policy outputs: What the system does - it is not restricted to tangible goods and services.

d) Policy outcomes: Consequences (impact) that result from political action and inaction.

By differentiating between the major dimensions, it becomes possible to define and explore the process of policy while being aware of its interconnectedness, interdependency, and the impact of policy decisions on various stakeholders at any given time.

The ultimate goal, therefore, is the systematic and scientific study of policy for duplication, verification, confirmation, improvement, and knowledge extension purposes. So, there is no one "best way" for policy-making. Furthermore, the nature and complexity of the policy problems often require a variety of approaches for effectively solving a problem. Each of the models tend to focus attention on "different aspect of politics and policy-making and seems more useful for some purposes or some situations than others." As such, "one should not permit oneself to be bound too rigidly or too dogmatically to a particular model" (Jenkins, 1978).

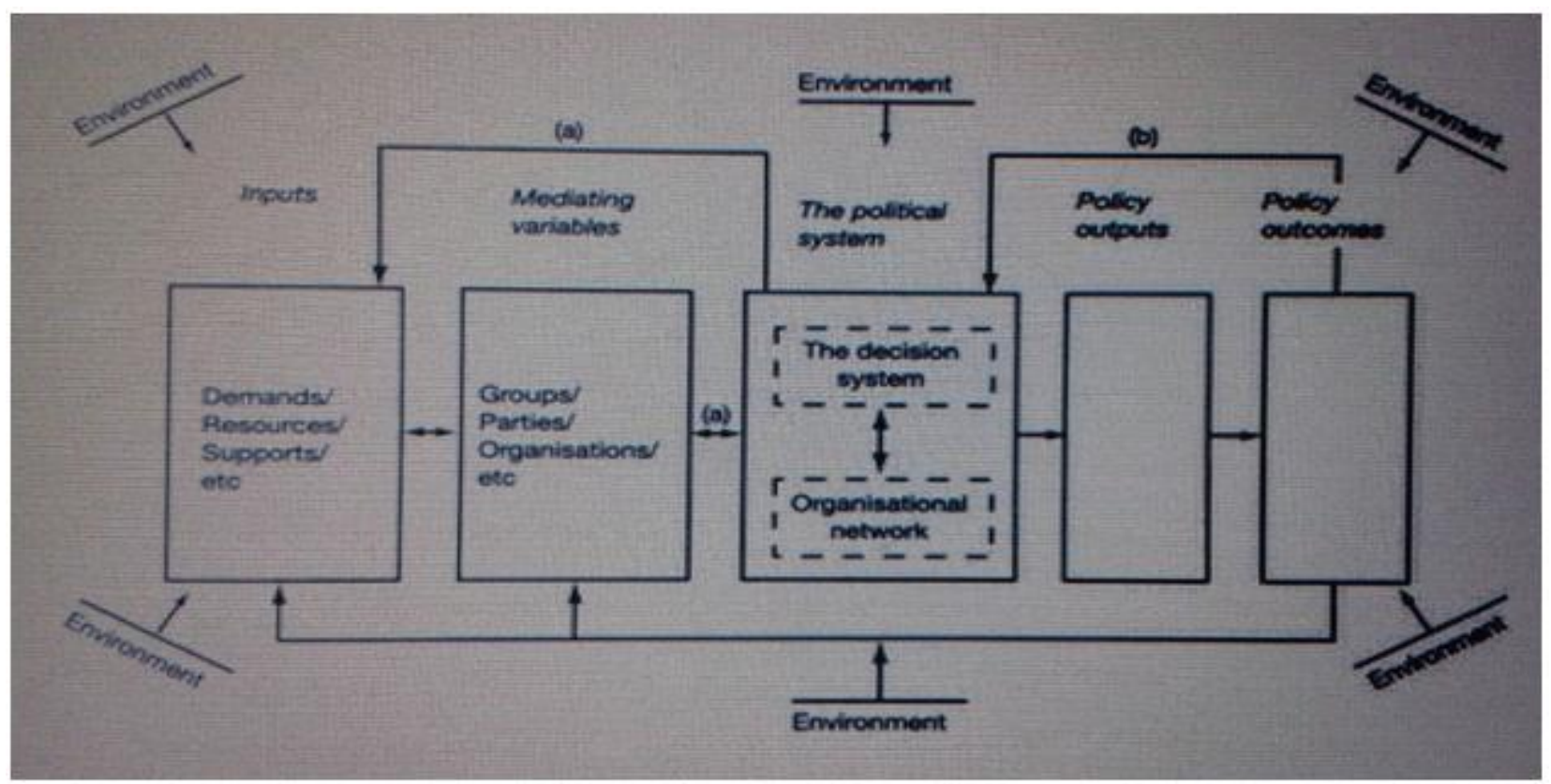

Source: Jenkins (1978)

Figure-2. Policy-Making Model (Jenkins, 1978) 
To explore the policy world, a more detailed conceptual or extended model is required. The extended model (as presented in Figure 2), and according to Jenkins (1978) the model can act as a useful heuristic map which is useful in alerting researchers and public sector as well as private sector decision-making in areas that need more attention. Furthermore, this extended approach can serve as a "bridge" between practice and theory. The focus of policy in this extended model is primarily a systemic one (holistic view). According to Jenkins, "public policy is best understood by considering the operation of a political system in its environment and by examining how such a system maintains itself and changes over time" (1978).

The environment is not without structure, as it is often made up of people, groups, and organizations operating independently or jointly based on diverse values and interests. The environment surrounds the whole process, influencing anything and everything. Of course, what actually passes for the "environment" variables requires careful thought and attention. It is doubtful that the policy process can be captured in any great detail by the simple linear "feedback" model. As such, interactions both across and within systems should be considered. Overall, policy analysts should explore the nature of the political system and the relationship between decision processes and outcomes. Exploring outcome requires establishing some conceptual grasp of motivation and behavior. As such, "an understanding of the behavior and motivation is central to an understanding of policy outcome and impact" (Jenkins, 1978). The extended model is not perfect; it is not an all-encompassing model. As such, it is open to criticism, testing, and improvements.

Overall, one can summarize that policy-makers should focus on how policies actually govern, and they should ask other questions that relate to why a policy must govern as they consider the ultimate well-being of all people in society (Rissmiller, 2000). As part of the policy development process, there can be a market orientation which focuses on privatization, marketization, and contracting out, which hopefully provides competition, thereby making products and services cheaper for consumers. There also should also be a dialogue orientation in order to focus on interaction between government agencies and civic groups. "Civic responsibility emphasizes obligations that citizens have to their society, and their government" (UNF Lecture, 2016). Civic responsibility focuses on the relationship of citizens to their government and society, and especially on the obligations of citizens to their society. Responsible citizenship has been grossly under-emphasized, both in terms of asserting the importance of this to citizens, and in training policy-makers and public managers on what to do in the face of irresponsible citizenry.

\section{Ethics, Policy-Making and Economic Development}

A leader today in the public and private sectors in creating and shaping policies and making decisions is expected to do so not "merely" in a practically efficacious and legal manner but also in a moral manner. Morality, perforce, brings one into the realm of philosophy, specifically, ethics, which is a branch of philosophy. There are many ethical theories and principles that one can use to ascertain the morality of a policy, decision, or action. For the purposes of this study the authors will discuss two ethical theories: Utilitarianism and Kantian ethics, both of which are secular-reasoned based Western Civilization ethical theories. Utilitarianism is an ethical theory created by the $18^{\text {th }}$ century English philosophers and social reformers, Jeremy Bentham and John Stuart Mill. The theory is a consequentialist ethical theory; that is, morality is determined by focusing in on all the stakeholders (also called "constituent groups) affected by the action. There is a predictive element to this ethical theory; that one must predict consequences as they affect each discrete stakeholder group, including society as a whole. Ethical Egoism (that is, the "selfish" theory to advance oneself and one's organization) is of course a consequentialist ethical theory too, but plainly with Utilitarianism the scope of analysis is much, much broader than merely oneself. Predicting the consequences of an action is obviously a challenging task, but the Utilitarians say, first, to use one's "common storehouse of knowledge" and to use "history as a guide." Second, one needs to look for probabilities of occurrences as well as the reasonably foreseeable consequences of putting an action into effect. Finally, one must attempt to measure and weight consequences, first, for each stakeholder group and then among all the stakeholders. Accordingly, if there are predominant good consequences the action is a moral action; and conversely, if there are predominant negative consequences the action is an immoral one. The goal of the Utilitarians was to seek to promote happiness, satisfaction, pleasure, but note that since the "ends justify the means" there can be some painful consequences produced but overall since there is more good an action can be deemed moral.

Kantian ethical theory is based on the moral philosophy of the $18^{\text {th }}$ century German philosopher and teacher, Immanuel Kant. Disregard consequences in determining morality, said Kant; and rather focus on the application of a formal test which Kant called the Categorical Imperative. "Categorical" because, declared Kant, this is the supreme and absolute ethical principle; and "Imperative" because one must at times command oneself, despite contrary self-interest, to do what the Categorical Imperative impels one to do; that is, to do the moral action regardless of consequences, even to oneself. By ethical reasoning from the Categorical Imperative one will logically be able to ascertain the moral course of action (Cavico and Mujtaba, 2013). Of course, one can clearly see the major conflict in secular-based ethics in Western Civilization since the Utilitarians focus on the consequences of an action in determining morality; whereas Kant says to disregard consequences and instead apply the Categorical Imperative. For the Utilitarians, the "ends justify the means"; but for Kant the means itself must be moral as per the Categorical Imperative (Cavico and Mujtaba, 2013). There are two main tests to the Categorical Imperative. One is called the Kingdom of Ends test. Pursuant to this test an action is moral if it treats people with dignity and respect and as a worthwhile means; as such, if an action is demeaning and disrespectful to people and if it treats them like a thing, tool, instrument, or means, even to a greater good overall, the action is immoral (Cavico and Mujtaba, 2013). Another test of the Categorical is called the Agent-Receiver test. In essence, it is the Golden Rule ("Do unto others what you would have them do unto you.") made secular by Kant. Pursuant to this test, an action is moral if one as a rational being and one did not know that one would be the giver, that is, the agent, of the action, or its receiver would be willing to have the action done. And if one would not want to be on the "receiving end" of the action, then it is immoral (Cavico and Mujtaba, 2013).

The ethical challenge for a leader today is to achieve actions that advance self-interest (Ethical Egoism), are culturally competent (that is, comply with societal moral norms pursuant to Ethical Relativism), and achieve 
greater good (Utilitarianism) (strive for "win-win" scenarios for all stakeholders), but do not demean or disrespect stakeholders (Kantian Ethics) (Cavico et al., 2015). The rationale for acting morally is simply Ethical Egoism, that is, it is in the long-term advancement and self-interest of a person, company, organization, or government entity to act morally. Companies, organizations, and government entities led by principled leaders who possess integrity and fulfill their legal and moral responsibilities will establish firms and agencies with a deserved reputation of good character and as a result their firms and agencies should do better financially and practically.

However, the role of a leader very well may be to educate people as to their own self-interest; that is, to show the way (to top management, the board of directors, and shareholders or government agency heads, legislators, and taxpayers) that acting morally will benefit the organization in the long-run. The role of a leader, moreover, is to create at one's company, organization, or government entity a culture of ethics that fosters and supports moral behavior; and the objective is to establish a personal and corporate/organizational reputation for integrity and trust (Cavico et al., 2015) because, to cite two business examples, as Wells Fargo and Volkswagen executives learned, once a reputation for trust is lost, it is very difficult to get it back. The role of the leaders at the aforementioned companies would be to try to figure out how to change the organizational cultures to one of honesty, integrity, and ethics. Furthermore, the role of a leader is to object if an action is illegal and immoral. That is, a true leader must "stand your ground"; disagree on principled grounds; and have the strength of character, courage, and conviction to do the "right thing" and not do the "wrong thing" (Cavico et al., 2015). The leader of a company, organization, or government entity must not only set an example of virtue, integrity, honesty, ethics, and morality but he or she must seek to impart these values to the employees of the company by means of ethics orientations, coursework, seminars, and training, as well as by establishing ethics officers, "hot-lines," ombudsmen, and other channels for "whistleblowing" (Cavico et al., 2015).

Leadership is obviously an important value in the public and private sector today. In addition to the points previously made by the authors regarding the duties of a leader, another responsibility of a leader is to be aware of his or her organization's "blind spots"; that is, to be cognizant of and to comprehend the weaknesses as well as strengths of the entity and its policies, procedures, and personnel. These "blind spots" must be identified as well as opportunities, of course. The astute and agile leader, therefore, should not be "blind-sided" by any weaknesses or improprieties in the organization, such as, again in the case of Volkswagen and Wells Fargo, the employees acting in an illegal and immoral manner. The true leader, as emphasized, must make sound decisions and promulgate effective policies which are also legal, moral, and socially responsible. Moreover, the leader must be proactive, that is, to act as a "shaper" and not a mere reactor. The true leader must anticipate problems and challenges, and then show the way to solving and overcoming them. The true leader, therefore, must lead the way. Yet no one is going to follow a leader, at least not for long, if he or she is not an ethical, honest, and trustworthy person. Thus, it is critical for the leader to embrace and demonstrate moral behavior and to establish an organizational culture of morality and ethics. Accordingly, the leader today in the private and public sector must be prepared for these issues and challenges; he or she thus must be concerned with not only the practical and legal performance of the company or government entity, but also its moral, socially responsible, and environmentally sound performance.

\section{Social Responsibility, Sustainability, and Economic Development}

Another current societal expectation, and thus a responsibility for leaders, policy-makers, decision-makers as well future leaders, is to create policies that will encourage people to act in a socially responsible manner by being cognizant of the nature and importance of "sustainability" which is a concept tied to the values of law, ethics, and social and environmental responsibility (Mujtaba, 2014). The most frequently cited definition of sustainable development was published by the United Nations (Our Common Future, Chapter 2, Report of the World Commission on Environment and Development, 1987, p. 24): "Sustainable development is development that meets the needs of the present without compromising the ability of future generations to meet their own needs." Sustainability is a broad and all-encompassing concept since it can be interpreted as a MEANS (typically in the form of beneficial environmental actions, such as "green" buildings and offices, reducing green-house gasses, and otherwise reducing the firm's "environmental footprint") and also as an ENDS (that is, having a sustainable organization, society, as well as a sustainable planet, for future generations) (Cavico and Mujtaba, 2016).

An important challenge for policy-makers is that each person is expected to act in a socially and environmentally responsible manner (Cheretis and Mujtaba, 2014). This expectation is critically important for leaders and decision-makers in the public and private sectors. The societal expectation of this responsibility is thus above and beyond the law as well as morality/ethics (Cavico et al., 2015). Business, therefore, is expected to be a "good corporate citizen" (even though there may be no legal obligation to do so); and government leaders are expected to be good "public servants." Social and environmental responsibility is related to sustainability as a goal; that is, if we restore or preserve our natural resources and communities, we will also increase our chances of sustaining ourselves as a business, government entity, or a society. The old concept of seeing the purpose of business as only short-term profit is being increasingly replaced by a broader accounting framework, which includes three dimensions of measurement: "People, Planet, Profits," also called the "Triple Bottom Line" economic prosperity, environmental stewardship, and social responsibility (Cavico et al., 2015).

We all have the responsibility, therefore, to develop leaders in the public and private sectors with a sustainability mindset, who think and act in socially and environmentally responsible ways. For the business leader, who has a fiduciary duty to the owners or shareholders, the challenging objective is to achieve the "right" amount of social responsibility, that is, a prudent and moderate amount. Another important challenge for business leaders is to question: What type of social/environmental responsibility is recommended? Socially responsible actions and activities can be tied to the image, brand, products, and services of the business. The objective is for people, the community, and the planet to "flourish" (Mujtaba, 2015). These are all obviously beneficial actions to society and ones that demonstrate that a company is a "socially responsible" and "sustainable" one; and the actions will benefit these companies too; and a company should not be shy in getting some good publicity to show off their social responsibility and sustainability bona fides. And it is not merely community and government that will be impressed by a company's "green” efforts, but so will customers, consumers, and the employees. 
Particularly when addressing the millennials, business leaders have an opportunity to tap into and to heighten their sense of responsibility and forward-looking perspectives. The newly hired employees and future leaders, therefore, can, and should, be early-on introduced to the challenges and opportunities of business today, thereby preparing them for a competitive environment where social responsibility and sustainability are challenges, and mastering them is the result of strategic decision-making, featuring a "360 degree" perspective encompassing all the firm's stakeholders. The interest of future leaders can be awakened, and their acceptance gained. As such, one must underscore the benefits to the individual, the organization, the community, society, and the planet in which we all live and want to do business in; and also one must inspire future leaders by means of real and current examples of ways to be profitable while "making a difference" in society.

The rationale for being socially and environmentally responsible, and one that must be underscored to the future leaders throughout their socialization in the company, is the maximization of their own self-interest along with that of their firms, communities, and society as a whole. That is, the instrumental worth of being a "socially responsible" person and organization, in addition to being a legal and moral one, will be the advancement of one's own self-interest, the company's self-interest, and the corresponding benefit to community and society as a whole, as well as the sustainability of the planet for future generations. Table 1 presents a few actual recent examples of how employees and organizations can be creative in acting with a sustainability consciousness mindset to keep the environment "clean and green" (Mujtaba et al., 2016).

Table-1. Examples of Reusing and Recycling

Mujtaba et al. (2016)
Staples.
The first example, from the Institute of International Studies (IIS), is the staple singulars. Instead of
throwing away the used staples, each staff member competes with others in collecting them for recycling. Then
we donate all of them to be recycled for producing walkers for people with walking disabilities and the elderly.
Nearly over one pound of them is just the staples collected from one office over the past six months. Just
imagine how many staples could be recycled over a 2, 3 years or even a 1O-year period. The staff members are
also enjoying this activity as it is fun and helps in making the world a better place for us and future
generations.

\section{Printing Slips at 7-11.}

The second example comes from what they do at most of the 7-11 stores in Bangkok. They reduced the customer receipt slip size by $1 \mathrm{~cm}$. in order to save paper and the trees from being cut down. In this process, they can save many trees from being used for paper production as they use tens of millions rolls of paper each year since Thailand has more than 8,000 branches nationwide. This is an example of good operational management for sustainability and saving the world by reducing their usage of paper by 4,680 km. per year. This length of paper savings is almost 3 times longer than the entire country of Thailand.

\section{CPF Company.}

The third example is CPF Company, which has more than 600 tons of frying product per month, like chicken frying. In other words, they use a lot of oil; therefore, producing the Biodiesel is the best choice. Using biodiesel means that they can manage their operations with oil usage of only around 90,000 liters per month. It is a good policy to produce Biodiesel B1OO to replace using diesel. Most importantly, this helps in reducing the risk of cancer. It is the project of the late King Bhumibol for the Renewable Energy.

\section{Selling Garbage.}

The fourth example is Lumpini Condominiums where they separate the garbage as some parts of can be used for selling. The amount of money that they receive from selling garbage that is thrown out by living residence is used to improve the appearance of the condos, and sometime they donate some of the funds to help the poor. This is an example of what apartment and condo owners can integrate into their operations to make the world a bit more sustainable over time.

\section{Shoe Recycling.}

The last example is Niki Company as they collect the old shoes that are no longer needed and they blend the soles of shoes which can be safely used in the playground for children. Instead of being thrown out, the soles of these shows are used again to create a safe playground for children in the neighborhood parks. This is an example of what a company can do to make its new and used products more useful for the communities where their customers live.

Source: Cavico et al. (2015)

Leaders in the private and public sectors can create the best future by planning for it with specific goals, organizing and devoting relevant resources, having measureable milestones, and specifying action plans that can be controlled. Leadership is about having a vision, influence and the ability to execute a practical strategy into action; and this ability should be used to make society a little better through our operations in each organization. The authors have emphasized that the business leader today will confront societal expectations that the business will not merely act in a prudent economic and correct legal manner, but also that the business will act in a moral and ethical and socially and environmentally responsible manner.

\section{Future Research}

Ethical maturity and sustainability are critical components and pillars of policy-making and a continually prospering economy. As such, it is important for public and private sector leaders, managers, and employees to act not only ethically in making decisions but also to integrate sustainability into their operations. Accordingly, an example of a research question for further study is as follows: Is there a statistically significant relationship between the ethical maturity (cognizance) and sustainability consciousness levels of public sector managers compared to those in the private industries? Data could be collected using a survey instrument such as the Personal Business Ethics Scores Survey 
(PBES), which is based on a Likert Scale rating of 1-5, along with a few added questions regarding sustainability consciousness / awareness. Future researchers can test to see if gender, age, education, and management experience play a role in the ethical maturity and sustainability consciousness of public sector managers and employees. Moreover, and very interesting indeed researchers could try to ascertain whether ethics education and/or training are related to ethical maturity (cognizance) or sustainability consciousness. One would think that there would be a relationship between ethics and sustainability as well as between ethics education/education and morality; but some corroborating data would be most helpful indeed to expanding the body of knowledge in these fields.

A review of public administration literature demonstrates that there are no empirical studies focusing on the relationship between the two constructs of ethical maturity and sustainability consciousness with public sector managers. As such, a study will fill the gap in existing literature through empirically testing the relationship between ethical maturity and sustainability consciousness of public sector managers using various demographic variables. The study can conjecture that public sector managers and employees are more likely to have a higher level of ethical maturity and sustainability consciousness with servant leadership mindset as compared to nonpublic sector working adults; as such, their desires for employment are likely to be driven by serving people and their communities rather than selecting professions only for prestige, profit, and power.

\section{Summary}

The objective of sustainable global leadership and policy-making is to make sure the processes used for economic developments along with their associated outcomes are more successful, socially and environmentally responsible, and continually sustainable. This "sustainability" mindset is the way to achieve long-term economic success and sustainability; and thus future business leaders must be developed and prepared to do what is the essence of leadership, and that is to "know the way," "go the way," and "show the way." Consequently, the challenge for the policy maker today is to have that mindset and thus to fulfill these expectations, meet these challenges, achieve tangible success, and to sustain that success for the business and government entity and all their stakeholders, including society as a whole, the planet, and future generations.

This study examined the critical interrelationship among leadership, policy- and decision-making, ethics, social responsibility, and sustainability in the context of both the private and public sector. The study focused on policies that would enhance economic development in a sustainable manner. For the public sector, it is important that policy-makers, leaders, managers, and employees have a "servant-leadership" mindset, encompassing higher levels of ethical maturity and sustainability consciousness, in order to bring about progressive economic development for the local community and society as a whole. If public and private sector policy-makers, leaders, managers, and employees do have higher levels of ethical maturity and cognizance as well as social responsibility and sustainability consciousness, then their policies, decisions, and actions will benefit everyone in society, the planet, and future generations. A leader, in particular, must naturally make sound decisions and promulgate good policies, which are legal and achieve results; but the leader must also act and ensure that these decisions and policies are moral, socially responsible, environmentally responsible, and therefore sustainable. In essence, the leader's "sustainability" mindset in the policy-making process is quite simple and straightforward, that is, to ask, and to answer the following questions: Is the policy effective? Is it moral? Is it socially responsible? Is it sustainable as a MEANS (That is, is it environmentally responsible?)? And, finally, and most critically, is it thereby sustainable as an ENDS?

\section{References}

Anderson, J.D., 1997. Public policymaking. 3rd Edn., New York: Houghton Mifflin Company.

Cavico, F.J. and B.G. Mujtaba, 2013. Business ethics: The moral foundation of effective leadership, management, and entrepren eurship. 3rd Edn., Boston, MA: Pearson Publishing.

Cavico, F.J. and B.G. Mujtaba, 2016. Developing a legal, ethical, and socially responsible mindset for sustainable leadership. Florida: ILEAD Academy.

Cavico, F.J., B.G. Mujtaba, G. Nonet, I. Rimanoczy and M. Samuel, 2015. Developing a legal, ethical, and socially responsible mindset for business leadership. Advances in Social Sciences Research Journal, 2(6): 09-26.

Cheretis, D. and B.G. Mujtaba, 2014. Maximizing long-term value and conscious capitalism at whole foods. SAM Advanced Management Journal, 79(3): 4-16. View at Google Scholar

Dye, T., 1998. Understanding public policy. Upper Saddle River, NJ: Prentice-Hall, Inc.

Jenkins, W.I., 1978. Policy analysis. A political and organisational perspective. London: Martin Robertson. pp: 15-25.

Mujtaba, B.G., 2014. Managerial skills and practices for global leadership. Florida: ILEAD Academy.

Mujtaba, B.G., 2015. Climate change and sustainability. YouTube Video. Retrieved from https:// www.youtube.com/watch? $?=y$ QbCyUxB4co.

Mujtaba, B.G., F.J. Cavico, T. Senathip and S. U-tantada, 2016. Sustainable operational management for effective leadership and efficiency in the modern global workplace. International Journal of Recent Advances in Organizational Behaviour and Decision Sciences, 2(1): 673-696. View at Google Scholar

Ping, H., B.G. Mujtaba, D.A. Whetten and Y. Wei, 2012. Leader personality characteristics and upward trust: A study of employeesupervisor dyads in China. Journal of Applied Business Research, 28(5): 1001-1016. View at Google Scholar | View at Publisher

Rissmiller, K., 2000. Approaching a model of policy change: A challenge to political science. Proceedings of the Eighteenth International Conference of the System Dynamics Society. August 6 - 10, 2000. Bergen, Norway.

Senathip, T., 2015. Protests in Thailand of the book entitled gender, education, and employment developments in South Asia: A review of progress in Afghanistan and Pakistan by B. G. Mujtaba. Florida: ILEAD Academy. pp: 197-199.

Susser, B., 1992. Approaches to the study of politics. New York: Macmillan Publishing.

U-Tantada, S., B.G. Mujtaba, M. Yolles and A. Shoosanuk, 2016. Sufficiency economy and sustainability. Proceedings of the 2nd Multidisciplinary Research and Innovation for Globally Sustainable Development (MRIGSD) - Valaya Alongkorn Rajabhat University. Journal of Thai Interdisciplinary Research, 2559: 84-94.

UNF Lecture, 2016. Paradigms of public administration. University of North Florida - Department of Political Science; PAD 4003 Public Administration. Retrieved from www.unf.edu/ g.candler/PAD4003/02.pdf. 


\section{Bibliography}

Easton, D., 1965A. A framework for political analysis. Englewood Cliffs, NJ: Prentice-Hall Publishers.

Easton, D., 1965B. A systems analysis of political life. New York: John Wiley and Sons.

Miyakawa, T., 2000. The science of public policy: Essential readings in policy sciences II. New York: Routledge, 5(1): 44-52.

Ventriss, C., 1989. Toward a public philosophy of public administration: A civic perspective of the public. Public Administration Review, 49(2): 173-179. View at Google Scholar | View at Publisher

World Bank, 1982. World development report 1982: International development trends, agriculture and economic development, world development indicators. New York: Oxford University Press. 